\title{
Just jokes! Icebreakers, innuendo, teasing and talking: The role of humour in HIV/AIDS peer education among university students
}

\author{
Silvie Cooper and David Dickinson
}

Department of Sociology, University of the Witwatersrand, Private Bag 3, Wits, 2050, Johannesburg, South Africa

\begin{abstract}
Peer conversation provides an important platform for people to explore and disseminate sexual health knowledge. Humour forms part of conversations held between peers including those where sexual health and sexual decisions are discussed. The central argument of this article links conversation, humour and peer education. Drawing on interviews and diaries kept by 12 student peer educators over a two-month period in a South African university, the article explores the forms and functions of humour in instigating and encouraging informal peer education between young people in a university setting. The evidence shows that humour can foster intimacy, familiarity and camaraderie in peer interactions; keeps conversation moving; and acts as a gateway to discussion of taboo, personal and private subjects that lie at the core of effective peer education. Components of humour (joking, teasing, innuendo, provocation) and the transformation of the serious (and boring) into the enjoyable (and accessible) are found in these peer interactions. However, humour can also limit communication by keeping conversations light and superficial or, in the case of inappropriate humour, close conversation altogether. Acknowledging the nuances of humour within conversation and peer education allows for a clearer understanding of the ways in which humour contributes to effective health promotion efforts and how it can be used within peer educator practice. The effect of the personality traits of peer educators on effective use of humour in conversation is an area that could benefit from further insight and research.
\end{abstract}

Keywords: humour, informal peer education, sexual health, taboo, university settings, young people

\section{Introduction}

This paper explores the role of humour in informal HIV/ AIDS peer education. Peer education involves the horizontal sharing of information, values and behaviours between people of similar ages or status groups. Peer education has both formal and informal aspects. Green (2001: 65), drawing on Sciacca (1987), argues that much peer education happens within casual interaction through informal social networks. Informal peer education can occur in one-on-one settings or in group interactions. In South Africa, peer education programmes involve the training and support of peer educators in order for them to engage in horizontal education and behavioural change efforts with their peers. These programmes particularly focus on topics of HIV/AIDS, sexual health and sexual relationships. These programmes are organised by a range of institutions, including companies, unions, schools, churches and universities (UNESCO 1999).

This paper draws on the findings of a research project undertaken with student peer educators at Wits University, Johannesburg. Over a two-month period, 12 student peer educators recorded interactions, debates and conversations that they had with peers in which sexual decision making appeared in the discussion (Cooper 2011). These interactions took the form of one-to-one discussions and group conversations and were additional to the array of more formal activities which the peer educators conducted as part of the university's Peer Volunteer Programme (PVP) organised by the Careers, Counselling and Development Unit (CCDU). The CCDU is an institutional resource for Wits students 
and staff and offers a range of services such as counselling, career advice and HIV/AIDS education and advocacy (CCDU 2011).

The peer educators' diaries illustrated how, for university students, traditional, primary sources of socialisation, namely family and educative structures, retreated as the individual moved into the often highly sexualised environment of the university. In this context there was a plethora of perspectives, opinions, practices and health knowledge available. The diaries revealed peer educators as one source of assistance to fellow students as they navigated their way through this tumultuous and diverse social space (Cooper 2011).

Informal peer education occurred much more commonly with this group of peer educators than the formal activities prescribed and organised by the PVP. In their diaries the peer educators collectively reported 118 informal conversations in which sexual decision making was discussed. Formal peer education activities typically took place twice a semester. These formal initiatives were topical in nature and related to campaigns addressing voluntary counselling and testing for HIV, sexual harassment and awareness of the dangers of mixing alcohol and sex. The diary entries showed that humour was frequently present in informal peer interactions where sexual decisions appeared as conversation topics. Group discussions, both formal and informal, were characterised by the presence of humour with seemingly serious topics being skirted over in favour of keeping the interaction light, humorous and fun. This paper argues that humour played a functional role in shaping and encouraging conversation into instances of peer education.

Overall, we argue that humour fosters a space where familiarity between participants in an interaction is displayed, and created, by the ability to 'share a joke'. The capacity to tease, play with innuendo, and use 'icebreakers' creates intimacy and security for young people engaged in conversations with peers. Humour reduces tension and embarrassment surrounding sexual health discussions and allows people to share, debate and contest perspectives, opinions and thoughts in a horizontal and supportive manner. This research revealed the productive capacity of humour in generating discussion and facilitating conversation intimacy in which peer education can occur. Humour should be recognised for its ability to draw in an audience, captivate their attention and allow educative moments of sharing and discussion to transpire. That said, humour is often avoided in peer education programme management and training, because of the risk of reducing the importance of the message or of the interaction veering into mocking. Furthermore, concerns have been raised about using humour use when the roles and skills of peer educators blur between the formal and informal. These distinctions are acknowledged and the negative or harmful aspects of humour are recognised. Overall, however, this research provides evidence that the productive, positive roles of humour appeared spontaneously and frequently in formal and informal settings, while additionally encouraging and facilitating moments of informal peer education.

This article outlines the background and rationale of the study and the theoretical framework that underpinned the research. Thereafter the components of peer education are elaborated and the link between conversation and humour is made. The methods utilised in this research as well as the key findings, analysis and conclusions are then provided.

\section{Background}

This paper was developed from a larger research project which explored the role of peer educators in their peers' negotiation of sexual decisions. The research project uncovered the ways in which CCDU peer educators translated strategies and information garnered within formal peer education training and activities into the informal spaces of conversations with peers about sexual decisions. The term 
'sexual decision' refers to a broader set of processes, discussions, beliefs and perceptions that assist or inhibit particular courses of action being taken with regard to sexual activity. For example, whether someone is a suitable sexual partner, whether contraceptives (and what type) will be used and the appropriate time to engage in sexual activity all qualify as sexual decisions (Cooper 2011). Emerging from this research process was the importance of humour in sparking and fuelling conversations that overlapped with and contained moments of informal peer education.

Students are an important group to study given the psychosocial, cultural and developmental changes many of them experience in the transition from school to university. As young people integrate into a more broadly sexualised world where contradictory and conflicting ideas about sex exist, understanding how they draw on assistance in negotiating this terrain is both useful and necessary. Visser (2007) explains that the youth, including young adults, are at risk of contracting HIV/AIDS and other sexually transmitted diseases (STDs) because they engage in high-risk sexual behaviour although they have sound knowledge about sexual health risks. For Visser (2007: 679), if interventions, especially prevention and health promotion programmes, are to be effective then these initiatives should be developed specifically to "match the culture, age and sexual experience of participants".

Implementing peer education programmes in university environments can be challenging. Because universities encompass such a diverse range of activities, there is little opportunity to institute concerted efforts to engage students on issues of sexual health while on campus in a productive, educative and sustainable manner. Johnson et al. (2007) explore the complex process of age identity in the transitionary space between internal, self-perceived adulthood and broader external, societal age-appropriate expectation. This process can be difficult to comprehend as social conditions of familial structure breakdown, economic factors, extended education, racial, ethnic and cultural values and practices muddle the meanings of markers that indicate definite changes in social identity (Ochieng 2003, Johnson et al. 2007).

Giddens (2006) states that socialisation is a continual process which occurs as an individual shapes their identity. Along with family, schools, religion and mass media, peers are an important socialising agent for the individual. Giddens (2006) notes that compared with the family, less is known about how influential and significant peer groups are in the individual's experience of socialisation, however, the relations between peer groups and the individual member are likely to have a considerable effect on perceptions and behaviour that are not discussed with other socialising sources.

Peers can also play a crucial socialising role where school, family and religion have become inaccessible and less influential as sources of knowledge around sex and sexual decisions. Campbell and MacPhail (2002: 338) note that teenagers who have "opportunities to communicate openly about sex, with sexual partners, peers and parents or other significant adults" are more likely to engage in safe sexual behaviour. Peer educators can then be instrumental in creating these opportunities and spaces for discussion and consultation, and can also sources of knowledge which reinforce or contradict thoughts and ideas held about sex.

Informal peer education can be seen as an effective means of assisting individuals to navigate through this terrain as the process is already embedded within the social environment and is being utilised in an unacknowledged, unscripted manner. Partly for the reasons discussed above, peer educators can be a valuable resource in disseminating and processing information about sexual health, particularly in the transitional and turbulent social environment found in university settings. Additionally, in the context of the high HIV/AIDS prevalence found in South Africa, opportunities to engage with young people around issues of sexual health are important to garner, and peer educators are frequently used for these interventions. 


\section{Peer education: Formal and informal aspects}

Peer education is characterised by the moments in conversation where commonality in age or background encourages the emergence of a process of discussing, exploring, challenging and internalising information, values, beliefs and behaviour. Peer education has both formal and informal aspects. Green (2001) discusses the difficulty in identifying the distinction between formal and informal peer education, but shows that the space and format of the discussion is usually indicative of the type of peer education taking place, with formal peer education being planned, purposive and direct in nature. For Turner and Shepherd (1999), peer education varies in its methods depending on the context and target group of the information being circulated. Formal peer education closely resembles the methods and structure of formal tutoring in terms of whole group teaching in set meeting places of schools or youth centres. In contrast, informal methods of peer education appear in the casual discussions that occur spontaneously in the course of social life among people in similar life stages.

Peer education initiatives have mostly been located within workplaces and schools, where organisation is relatively easy. There have also been attempts to target populations seen to be at high risk of contracting HIV/AIDS, such as sex workers, young people who are becoming sexually active and migrant labourers (UNESCO 1999). It is easier to institute formal educative structures within formal institutions as an organisational culture also exists with high levels of supervision in place that allows monitoring and implementation of programmes in a top-down manner. There is also a largely stable population to educate (UNESCO 1999). Peer education studies focus more on the formal aspects of the practice, particularly understanding implementation, monitoring and evaluation and creating conducive environments for the practice to occur (Campbell and MacPhail 2002, Visser 2007). Within this body of literature the informal aspects of peer education are largely unacknowledged (Dickinson 2009). Furthermore, little is known about the role of humour in peer education, particularly in informal settings (Cooper 2011).

For Shepherd et al. (1997), there is much complexity and difficulty associated with evaluating the effectiveness of informal peer education, as the process is often spontaneous in nature and incorporates different sets of knowledge and skill which are demanding and hard to view comprehensively. Other aspects and factors within the peer education process take precedence over informal education, such as programme design, implementation, effectiveness and outcomes. This often means that the nuanced practice of peer education, as well as the spaces in which it occurs, is neglected within the plethora of health promotion and education literature related to this area (Ochieng 2003). Dickinson (2009) suggests that, within the workplace, a combined approach acknowledging informal and formal peer education can have a greater effect on the way people conceptualise and understand HIV/AIDS and bring about behaviour change. For these reasons it is important to acknowledge and include research that focuses on the informal aspects of the practice.

Many behaviour change theories are used in peer education theory, including the Health Belief Model, AIDS Risk Reduction Model, Stages of Change, Diffusion of Innovation Theory and Theory of Reasoned Action (Green 2003, Nutbeam 2006). The most relevant of these to the findings analysed in this research, that looked at informal peer education in a university setting, is Stages of Change which sees "behaviour change [as] a process, not an event, and that individuals have different levels of motivation or readiness to change" (Nutbeam 2006: 32-33). This process involves identifying an issue, fostering the appropriate environment to broach that issue, space to consult and discuss before deciding on a course of action and then enforcing that plan and subsequently maintaining the behaviours put in place to deal with the initial issue. In this case, it is negotiating sexual decisions with the assistance of peers. We propose that humour can be seen as part of the process of creating the appropriate 
environment as it generates intimacy, reduces tension and encourages discussion of topics that are generally seen as sensitive, personal and taboo.

Campbell and MacPhail (2002) explain that peer educational settings allow for diversity in opinion within a changing group process. For Campbell and MacPhail (2002: 333) "individual inputs weave and clash through the process of dialogue and argument between peers" and in questioning each other, sharing stories and experiences, a forum is ideally created where different behavioural possibilities are examined and judged. For the peer educators involved in the research, being at university proved to be an opportune space to assess, critique, challenge, accept and reject various aspects of their sexual health, as well as assist peers in doing this too (Cooper 2011). These opportunities emerged in the discussions held with their peers where they were able to talk informally and openly about various aspects of social and sexual identity in between the chaotic, disordered, and usually unplanned course of their conversation. These conversations emerged as a platform from which peer educators and their peers could deconstruct and disseminate discourse about sexual decisions and health in ways that amount to informal peer education practice.

\section{Conversation, humour and peer education}

Within peer education literature there is little mention of humour as a communicative tool. Yet given humour's persuasive role in easing tensions and allowing difficult topics to be broached, it is clear that attention should be given to this potentially facilitative component of communication that can foster a conducive environment for peer education to occur. Participants in these conversations are encouraged, through the use of humour, to feel comfortable enough to share and discuss thoughts, opinions and experiences with other people in their peer circle. By using humour in their conversations, peer educators and their peers are able to engage and move through processes of socialisation with each other where perspectives and discussions related to sexual health can be unpacked and worked through in accessible, assistive and educative ways.

The gap found in relation to humour in peer education perspectives could be attributed to the general failing of humour research to understand those instances of humour that are unrehearsed, hidden or embedded in informal social situations (Meyer 2000). According to Meyer (2000), the four functions of humour are identification, clarification, differentiation and enforcement and each function can correlate with a particular theory of humour. For Meyer (2000: 317) humour in social situations (such as informal conversations) can act as "a 'lubricant' and an 'abrasive'... [as it can] smooth the way and integrate a [speaker] into a greater level of credibility within a group, but it can also ruffle feathers and cause social friction and conflict". This ambiguity is what Meyer (2000:329) characterises as the "double-edged sword" of humour which speaks to the relationship between social context, audience, speaker and conversation content. Depending on these factors, humour can act as a unifier, drawing people together and fostering comfortable relations between participants, or alternatively it can serve to divide the audience from the presenter and create a tense environment which does not encourage or facilitate effective discussions (Meyer 2000).

When dealing with topics as sensitive and contested as sexual decisions, humour can draw participants into a conversation more readily, and sustain their interest while encouraging the discursive, sharing space of peer education to form. Simultaneously, humour can alienate and push people away from the discussion if the humour is viewed as being out of place, inappropriate or unnecessary. Specifically, Meyer (2000) states that humour that lets the presenter (in this case a peer educator or their peer) show they can laugh at themselves and with others can increase accessibility to the peer group. In turn, this allows them to invoke "an issue very familiar to the audience, as well as placing the target of humour in a position of sharing meaning or perspective on that issue" (Meyer 2000: 319). 
The fleeting and unplanned nature of informal interactions means that communicators (peer educators or their peers) do 'package' their beliefs and stories and relate them to their peers in humorous ways. Humour can be used when young people are navigating and negotiating their way through a body of sexual health and decision making discourse which is rife with contradiction and tension.

The research supports the positive aspects of using humour as a communication device, but also displayed instances of the potentially harmful use of humour, thereby demonstrating the "doubleedged sword" that Meyer (2000: 329) describes. Central to understanding informal peer education, then, is a recognition of the manner in which it runs along the same communication paths as ordinary conversation; a process imbued with emotions, habits, familiarity, intimacy, comfort, distance and difficulty. Humour, as a component of communication, is a salient tool in facilitating conversations between peer educators and peers generally, and the focus of this article is in the opportunities it provides to transform everyday talk into informal peer education.

\section{Methods}

Unobtrusive observation of humour within peer interaction presents methodological challenges. The primary mechanism used in this research was keeping diaries. Student peer educators were asked to record and reflect on instances, interactions and conversations with peers which contained discussion relating to sexual health and decision making.

The University of the Witwatersrand, Johannesburg (Wits) is described as a "medium-sized urban contact university, English-medium and research focused, with 20 percent of its student population living in residences" by CHE (2008: 7). Black African students constitute $66 \%$ of the student population and just over half the students are female. The HIV prevalence rate among students enrolled at tertiary institutions is relatively low (3.4\%) and well below the national rate for the same age group (Berry 2010). Of the 30 student peer educators approached through the Wits Peer Volunteer Programme, 12 participated in all stages of the research. Of the racially diverse cohort, there were eight women and four men; five of them were living in the university residence.

The study was exploratory in nature, phenomenological and qualitative in approach. The primary form of data collection method used was diaries, kept by the peer educators. Participants kept the diaries for a period of 2 months with a total of 118 interactions being reported in that time. Data were also collected using a survey to assess the demographic background of peer educators. Additionally, a focus group session was held with 7 of the peer educators to establish their understanding and perspectives of peer education and sexual health, and 10 semi-structured interviews with individual peer educators were conducted. These interviews were primarily used to clarify entries in the diaries, expand upon issues raised and reflect jointly on the broader themes and findings of the research. This ensured that the researcher and the participants met often, and at all stages of the research process.

The frequent meetings between the researcher and the participants strengthened the sense of partnership involved in the research process. The peer educators were recording the activities they undertook in their day-to-day lives. They were operating largely unconsciously in these spaces and interactions and had little knowledge or ability to recognise what was useful, productive, limiting or an impediment in their actions and interactions. Meeting frequently with the researcher proved to be a helpful strategy for interpreting the content of the diaries. In requesting that they record their activities and presenting opportunities to reflect on the way in which they naturally are able to amplify moments that could contain informal peer education, a productive process of becoming conscious of their strengths and weaknesses, successes and areas for improvement could be teased out. Meeting 
so often with the researcher and developing an additional discourse around the diary content with the participants contributed greatly to the analysis of the data in bolstering and clarifying their perspectives while meeting the objective of working as research partners.

The research participants were approached as partners in the process and much attention was given in the study to ensure that there was reflexivity on the part of the researcher. Continuous consultation and feedback to the peer educators and the managers of the PVP was ensured. Ethics clearance for this research was granted by the Wits University Ethics Committee. Pseudonyms were used throughout to maintain the anonymity of participants. While the findings of the research are not generalisable, due to the case study nature of the project, they are nonetheless significant because they describe the deeply complex process of informal peer education which is notoriously difficult to capture empirically.

\section{Findings}

\section{Humour used to relieve tension around sexual and taboo subjects}

In the focus group workshop held with the peer educators at the start of the research process, humour was evidently contributing to making discussing sexual health and sexual decisions engaging, interesting and enjoyable. The peer educators themselves frequently giggled, laughed, teased, joked, used innuendo and provocative statements to challenge, comfort, draw out and encourage the perspectives of the group to emerge during the workshop. Humour kept the conversation moving and allowed people to reveal their opinions in a context that felt safe, familiar and accepting because the participants could tease each other and laugh together.

Despite this spontaneous use of humour by the peer educators, the CCDU running the peer educator programme discouraged the use of humour by peer educators when engaging peers, given the potential for humour to be interpreted as judgemental or demeaning when dealing with difficult and often very personal issues. Peer educators at Wits play a key role as peer counsellors at CCDU. In an initial meeting with the managers of the PVP, it was explained to the researchers that the three streams of activity (counselling, education and advocacy) undertaken by peer volunteers encompass different skills.

During the selection process, people recruited by CCDU are assessed to ensure that they have desired qualities and skills to be able to conduct the range of activities undertaken in their roles as peer counsellors. After an interview, people who are selected for the PVP are given 'foundation training' which includes discussion around what the individual understands by the terms 'volunteers', 'advocacy' and other roles and responsibilities related to their work with CCDU. Some components of the training focussed on self-awareness, personal growth and HIV/ AIDS which covers the virology of the illness as well as sexual harassment issues. The foundational training also teaches volunteers about the referral system set up for the programme, and how to use it.

Peer counselling is a branch of the PVP that only a few volunteers qualify for once they have received counselling skills training. The counselling stream of the PVP is a highly regulated and monitored component of the programme, with a formal system in place for counselling and referral. This is a role that requires intensive training and in the counselling sessions, humour use would be inappropriate. During a feedback session, the managers of the student peer educators expressed doubts regarding the potential blurring of roles and techniques. Specifically, they articulated concerns about humour being used by the peer educators over a range of settings. The managers also worried that humour might filter into formal peer counselling sessions where it could cause harm. However, humour formed part of CCDU events that involved the peer educators, with attempts to surprise their audience 
and retain their interest. In these interventions, serious messages about sexual health, such as the dangers of engaging in sexual activities when intoxicated, were brought home through the activity of spinning a person around before asking them to remove a condom from the package and then attempt to put it on a dildo. The difficulty in completing this task illustrated the difficulty of practising the safe sex recommendation of using condoms when intoxicated, and the message was viewed as memorable because it was fun and entertaining.

Therefore, peer educators involved in the CCDU programme used humour spontaneously when sex was discussed. The programme trusted them to participate in organised activities that were designed to be fun, but were cautioned about the use of humour when communicating with peers away from set activities. Yet, the peer educators' diaries revealed that humour was often present in conversations with peers that referred to sex, sexual health or related topics. Although there was no prompting for peer educators to record incidence of humour, 27 out of 118 recorded incidents related in the diaries included the presence of humour.

\section{Humour as a gateway to informal peer education}

Within informal interactions, recorded by peer educators in their diaries, topics relating to sexual health were not often presented in straightforward or explicit ways. Conversations had several topics that were superficially touched upon and there was frequent movement between topics. On several occasions humour could be seen as the tool through which the conversations were moved on to new and occasionally difficult topics, which could then be interrogated more concretely. Jokes in these conversations provided devices for changing the direction of the conversation, from one of 'everyday' topics to specific discussion around sex and provided the opportunity to transform the interaction into an educative moment. This makes the process of knowledge-sharing horizontal in nature as peer educators and their peers are relating through their communal sense of humour and therefore they feel on the same level as each other (Green 2001). Importantly, because these conversations are encouraged to emerge within this space through humour means that opportunities are created where questioning, debating and discussion of discourses, perspectives and experiences can be explored in educative ways (Campbell and MacPhail 2002).

Jokes act as an entry point for the taboo subject of sex. Themba, a 19-year-old BSc student, identified himself as a Christian of strong faith. In the interaction recorded below, Themba and his peer have a conversation about sex which becomes educative as the result of a joke:

'My neighbour at res[idence] asks to use the phone in my [room] to call a girl. The phone did not work and the guy was pissed [off]. In response, I jokingly (lol $\left.{ }^{1}\right)$ said he must not go and help himself (implying he must not [go and] masturbate). He laughed and seemed shocked [and] we then started talking about different sexual practices. He found it difficult to believe that guys masturbate and was disturbed by guy sex (a guy having sex with another guy). The discussion moved to [asking] what is sex about; why did God create sex? I said for 3 reasons: procreation (Genesis 1:28); strengthening relationships (Genesis 2:24); and for fun (Proverbs 3:18, 19).'

Latoya, who was 20 and enrolled in a BA course, described a conversation in her diary that was conducted in a humorous manner which allowed more serious, taboo topics to emerge:

\footnotetext{
1 'Lol' or 'LOL' refers to a term used by the peer educators in their diaries to indicate they found something in the interaction amusing. It is an abbreviated term meaning 'laughing out loud' that has become commonplace in written communication to denote that something is funny.
} 
'Today [I] was at a debating tournament [and] thus engaged with people and [we] had good laughter around the sex topic. I [heard] from the discussion how one girl's boyfriend broke up with her on suspicions that she was not ready to be sexually active in that relationship, even though the guy did not outright say it, but [he] gave irrelevant excuses, whereas, in the beginning, she made it clear that she was not yet on that level.'

It appears that within this situation, laughter acted as a tool to make participants more open and willing to engage on topics that might be viewed as inaccessible if not broached with humour. However, this laughter did not necessarily imply hilarity and humour, as the subject matter being discussed was in fact challenging: speaking about sexual expectation and rejection. In this instance, laughter played a role in turning a serious and personal topic into something to be shared in a socially appropriate manner.

It is an illustration of the facilitative, opening, topic-shifting capacity of humour which acts as a gateway to moments of informal peer education that took place in a secure and comfortable situation. Because humour is embedded in the ordinary, frequent conversations that emerge between peers, it is an important device for drawing participants into a discussion, retaining interest and smoothing over potentially divisive, difficult and tense topics. This supports Meyer's (2000) assertion that humour unites people, and therefore provides an intimate environment in conversation by highlighting their commonality because they share jokes and it means they find the same things funny.

\section{Ongoing conversation informally lubricated by humour}

Discussions between peers are not generally one-off events and within normal social interaction, they are ongoing. Having established intimacy over a usually taboo subject, this can be continuous. Humour plays a role in such discussions by maintaining them as fun and enjoyable, despite the serious, often taboo subjects that are under discussion which then convert into conversations with further opportunities for informal peer education to occur.

The ability to share a joke creates commonality between peers, allowing them to feel safe and comfortable sharing experiences, decisions and stories relating to sex. Sarah, a 20-year-old BA student, reported in her diary that it's: 'been an ongoing joke [in] the past few days with the boyfriend that he needs to buy some condoms and not "Choice"'. 'Choice' condoms are free, government-issue condoms and Sarah was negotiating her sexual debut with her boyfriend. Sarah shows how a joke that she continuously shares with her boyfriend allows them to discuss a difficult topic, such as condoms, in a manner that is comfortable, safe and particular to them.

In other instances of humour in this form, particular peer group participants were provocative or entertaining. This maintains expectations within the peer group that this person will introduce topics to the conversation that are likely to shock, amuse and entertain the collective. In doing so, there is regularity in the interaction and previous experience informs future expectations of discussions. Tim, a 20-year-old BSc student, met regularly with people in his residence and described how one peer often spoke about anything, regardless of the acceptability of the topic for the rest of the group. He reported that:

'Katloop is one fun character who almost talks about anything to amuse the rest. Tonight on his agenda was "fisting". My next door neighbour "Maria" and I were totally fascinated at hearing this. In disbelief she google searched 'fisting and an entire porn gallery surfaced. We were all shocked at the images displayed to us... Apparently lesbian sex involves fisting as a primary activity according to Katloop. Next infidelity was talked about and Katloop said that he would stay in the relationship provided that the sex was great, when I quizzed him about 
how he would handle the problem...Tonight was probably for me the most intriguing conversation I have had in a while. It was for great laughs although it's also a sensitive issue that we hardly joke about. It was fun...!'

Tim reflects on the effect of humour on his peer interactions by characterising the conversations he has as: 'joking, teasing and entertaining'. He also illustrates how the underlying perceptions, beliefs and experiences of his peers arise more readily if they can be conveyed humorously. It appears as if making light of the thoughts and behaviours they hold and enact will make them more acceptable to the group that the individual is presenting to.

\section{Humour and intimacy without learning}

Though shared laughter allows movement into a more intimate discussion, this is not necessarily a social space that is educative. Humour can become an end in itself with discussions being shallow in regard to their content about sexual health, even as sex provides the material for humour. This reinforces the point that humour is a potential, but not guaranteed, tool to achieve intimacy for peer education.

That peer education emerges in the myriad of ordinary conversations held between peers means that opportunities to perform the practice are sometimes lost in favour of keeping the conversation light, entertaining, humorous and casual. In such situations, humour can limit the extent and depth of a conversation necessary to enable peer education. In giving the conversation form and acting as a gateway to peer education, humour can displace serious discussion around sex if it is viewed as too sombre or dampening. Sarah shows how a gateway for discussing sex was opened in her conversation with friends, but was diverted into superficial and general conversation that had limited educative potential. She reported that:

I was sitting with some guy friends and was apologising for the third time for not making it to a get together he had on the Sunday. He then made a reference about how people "came and went" after I asked him how it was. This reference then turned into a discussion about how the girls CAME for him which lead to a discussion about which celebrities they (my two guy friends) would have sex with.'

This illustrates the multiplicity of peer interaction, where the discussion moves rapidly through many topics and the encouraging or limiting ways in which innuendo (in this instance) can be used to further a conversation towards an educative moment.

In the following interaction, Tim shows how humour played an integral role in shaping the course and outcomes of the conversation. The initial topic framed a taboo subject with laughter, making it an enjoyable and accessible discussion. Tim explained that:

'Masturbation was surprisingly a topic people were not keen on talking about because nobody wanted to admit having done it, but knowing me I broke the ice and set the mood for a laughter session-that was the only way we could share our experiences, by making them sound humorous!'

Later in the same encounter Tim was attempting to persuade his peer that the pre-and post-test counselling available with VCT for HIV/AIDS would prepare him for the outcome of an HIV/AIDS test regardless of the result. Tim challenged the perception held by his peer, namely that HIV/AIDS was such a threat to his peer's wellbeing that ignorance was a favourable option. Tim noted that humour can act as a barrier to further discussion on serious or threatening topics. The topic of testing was 
deemed to be serious and was rejected in favour of more humorous conversation, as 'only laughter was being entertained...'.

\section{Humour as hurtful}

There is a delicate line that distinguishes comfort and discomfort when humour is used in regard to personal, intimate or stigmatised issues. Meyer's (2000: 317 ) analysis of the dimensions and functions of humour illustrates how humour can act "as a 'lubricant' or as an 'abrasive"' in communication processes or a "double-edged sword". Humour characterises the relationship between social context, audience, speaker and conversation content and in this way acts as a unifier, drawing people together and fostering comfortable and good relations between participants. Alternatively, it might divide the audience from the presenter and create a tense and difficult environment which does not encourage or facilitate effective discussions. This is illustrated by Tim when a peer sought counsel and humour was used by Tim to relieve possibly his own feelings of awkwardness:

'Pretty came to "hang" (chill out) with me this morning after visiting a pharmacy. I was curious [about] what she bought and she showed me a post-exposure pregnancy tablet that would prevent her from becoming pregnant once she took it. Apparently whilst having sex with her boyfriend, the condom broke and he ejaculated within her. She was obviously horrified at what just happened. I then jokingly said that they should opt for love-making instead of violent sex!'

That Tim noticed his friend's distress over the circumstances that resulted in her having to take a postexposure contraceptive pill, but did not react sensitively to her predicament (in choosing to make a joke about it) shows that he used humour possibly as an attempt to reduce his own anxiety and discomfort with the situation. Fortunately, the friendship he shares with 'Pretty' allowed for this joke to be received in the spirit in which it was intended. Tim reported that after he made his comment Pretty added that: 'People can't always have boring and mundane sex (that's what we would consider love making). She only showed a lot of remorse for placing herself at risk'. Humour can therefore also be obstructive to the aims of peer education and this reveals the difficulty that peer educators face in dealing with 'friends' as opposed to 'peers' or 'colleagues'. Processes of communicating with them are not as clear or defined nor are 'appropriate' responses readily available to the educator in any given situation.

\section{Innuendo as risk mitigating when broaching difficult topics}

Humour can hurt and this is why it is downplayed in the Wits peer educator training. Shocking a peer presents a risky strategy - it may open up discussion, but it can also offend and close communication. Innuendo provides a low risk strategy: it can be picked up and laughed about or it can be ignored and forgotten.

Despite Themba's joking instruction that his peer should not 'go masturbate' after their conversation and the fact that the interaction discussed earlier arrived at a moment of informal peer education, it potentially could have been a very limited discussion. The peer's expression of shock showed that he was, at least initially, affronted by Themba's joke and found it disconcerting. If Themba's peer had not been able to laugh at the joke, that topic of conversation would not have emerged and the opportunity for Themba to perform informal peer education would have been lost. Humour in this form can be abrasive, rather than facilitative. By shocking people in conversation with a joke, dealing with taboo subjects can pique their interest and open discussion as previously described. Alternatively, it can create distance between the conversation participants with the joke 'backfiring' in terms of peer education. Subsequently this could be a reason for the reluctance of CCDU to promote the use of humour by peer educators away from controlled programmes. 
The room for misinterpretation of meaning around humorous statements is apparently too risky for it to be traditionally prescribed practise. While this concern is legitimate, the peer educators' diaries recorded no instances of humour being used hurtfully or in ways that severely limited discussion. The reasons for this could be that in testing the tone of a conversation, humour that borders on hurtfulness is diverted before the full effect can be felt in the general course and range of the discussion topics. Additionally, peer educators in the study may have reported memorable, successful conversations and therefore neglected to fully describe instances where the humour used was unproductive. In line with this argument, when people in the focus group discussion felt uncomfortable, rather than speaking out about it, they withdrew from the ongoing conversation. When queried about their quietness in subsequent interviews, some participants stated they were uncomfortable with the general discussion or felt they could not contribute as they held different views or had contrasting experiences from those being shared. However, most still enjoyed the discussion, were pleased to be present and part of it, and found the experience of the focus group engaging and interesting. Like the focus group, the diaries could reflect the experience of conversation when discomfort and memorable discussion intertwine to bring to light the positive, expressive components rather than the background, quiet elements.

Innuendo was frequently drawn on in peer conversations, where the joke, by being suggestive rather than explicit, was seen as safe and integrated the members of the conversation more firmly into the discussion. The safe jokes importantly contributed towards creating an overall sense of intimacy and easiness between conversation participants, and encouraged topics and discussions relating to sexual decisions to appear as illustrated in the following interaction reported in James' diary:

'II was] talking to my friend about sex because he and his girlfriend had been cooped up in the room. So obviously I made a joke over how much of an animal he was and we just started talking about whether the sex was good/not. What was startling was that he told me he never used protection.'

By using innuendo, peer educators like James and their peers were able to approach topics like sex, that are challenging to discuss, in entertaining and engaging ways. Innuendo allows discussion to move smoothly through and within topics, and it is a negotiating device for peers to test the acceptability of the humour.

\section{Peer education: Fun or dour?}

Humour appeared as a factor that potentially facilitated or inhibited educative opportunities in peer interactions. Specifically it lightened the tone of a conversation, converted topics considered taboo into general discussion, provided relief from nervousness and tension around potentially divisive issues, and fostered intimacy. It also made the overall experience of the conversation actively enjoyable and fun, rather than a dour, didactic process.

Angela, a 20-year-old BA student, reported an interaction with her classmates that demonstrated what enabled their discussions to be a 'fun' activity. Angela reported in her diary that:

'My friends from class and I were discussing sex in general and some of the important issues that I noted in this conversation were:

- We particularly debated about the right time a person may start having sex. This was interesting because some suggested that when one's emotionally ready, then this should serve as a point whereby a person may say that they are "ready". However, this contradicted others' 
suggestion of age. That is, concerns were raised whether for example, if a 13 year old is emotionally ready, then does that mean that they are ready to engage in sex?

- We also discussed the psychotherapeutic value of sex; however, people weren't particularly sure about this.

- I also observed how fun the conversation had turned out to be, because we ended up laughing at some of the "sexual gestures" that were being acted out.'

The impression given is that if participants in the interaction are comfortable sharing jokes then this indicates that they are on a similar level, thereby encouraging horizontal knowledge dissemination to occur. Humour, particularly in the capacity to generate intimacy, overcomes the barriers usually present in discussion of taboo subjects, such as feelings of insecurity, judgement and distance between peers. Many of the topics related to sex are also fearsome, challenging and difficult to discuss. In releasing the tension surrounding these topics by introducing them in a safe, comfortable, friendly, humorous manner, peer educators can create platforms and spaces for debating and discussing these matters in a way that is enjoyable. This process is characteristic of peer education and that humour intersects with and furthers the emergence of the practice is significant. It suggests that there is potential to develop humour as a concrete and productive tool in transferring sexual health knowledge between peer educators and their peers. Angela reflected on the nature of the discussion, and in saying that it was an enjoyable encounter as a direct result of the humour involved through her peers' use of 'sexual gestures', she also critically shows how humour can shape the experience of peer conversations in ways that encourage educative discussions. Humour is utilised by both peer educators and their peers, frequently and normatively in their conversations where peer education and discussion of sexual decisions can be found.

\section{Discussion}

Clearly, from the evidence outlined, humour plays a positive role in this process of peer education, notwithstanding genuine concerns that its use can be counterproductive. If humour as a communication device in informal peer education can be appropriately recognised, harnessed and utilised, some of the difficulties faced in creating opportunities and spaces of discussion can be overcome. In this way peer educators can play a crucial role in assisting their peers to negotiate their sexual decisions by being sources of consultation and discussion. The barriers that are broken down and the familiarity created by sharing jokes, humour and innuendo means that instantaneously people feel more comfortable with sharing experiences and perceptions that are profoundly personal and are often encouraged to remain private (Meyer 2000). In allowing people to explore and further understand the views they hold and explain their experiences, peer education could occur more readily and effectively through the appropriate and skilful use of humour. Many of the encounters reported in the diaries serve as reminders of the inexperience of these peer educators and the effects their experiences have on their ability to deal with issues within their social environment, as faced by them and their peers. Making jokes was acceptable for the conversation participants because of the intimacy of their friendship and the regularity of using humour to talk to each other. However, the seriousness of the subject matter being discussed can be lost through the use of humour.

These interactions occur as part of frequent meetings where participants discuss sex in a generally casual manner with the aim of sharing stories in entertaining ways. Humour is used to introduce topics and is drawn upon continuously throughout conversation to create an atmosphere that is comfortable and conducive to the sharing of opinions and thoughts. Talking about sex and sexual decision becomes a fun, enjoyable activity to participate in when humour encourages inclusion in a group and converts 
topics that are taboo and difficult to discuss into ones that appear 'lighter' and easier to speak about. Humour performed the function of a gateway and a driver to conversations which led to moments where informal peer education could take place.

\section{Conclusion and recommendations}

This research found that peer educators evidently talk to their peers about sex; and humour use, in part, shapes the process of converting ordinary discussion into moments of peer education. In a phase of life where other sources of socialisation, such as family or educative structures, become unavailable or inaccessible around the issue of sexual health, peers and peer conversation form an important platform to explore knowledge. The manner in which informal peer education echoes ordinary conversation shows that it finds it's trajectory from the interactions, relationships and discussions between peers. Additionally, understanding and harnessing the tools embedded within the practice can enhance, inform and support the ongoing endeavours of peer educators and programme managers.

As argued in this article, humour can facilitate the creation of safe spaces to discuss and question specific and often contentious aspects of sexual health in a way that encourages sharing and allows debate to develop. Humour assists this process by providing gateways and prompts for participants which in turn structures the atmosphere needed to discuss an area of social life seen as private and sensitive. This intersects with interactions that occur when the individual is approached in the role of the peer educator because they are known and regarded as a source of consultation due to their peer educator status. Humour is a communication tool that has different effects given a variety of factors including timing, appropriateness of the comment within the context, the content of the humorous statement and who the humour is being used with, why and where.

Humour enabled peer educators and their peers to initiate a discussion, but it also limited their ability to delve deeply into the underlying issues and implications thereof. In this instance, humour ensures that while the conversation can carry on in a relatively comfortable manner, it may also touch on sexual health issues in superficial ways. Additionally, when humour is inappropriate it can be harmful and therefore recognising the capacity of humour and training to use it productively in peer education needs to be considered. If humour is not harnessed appropriately topics which are genuinely serious may not be given the weight they deserve. As these concerns relating to sexual health and decisions present themselves more concretely in the society in which these young people operate, it is ever more important to appropriately equip the peer educators with skills and knowledge that allow them to be well-prepared and ready for the diversity and difficulty of the topics they might encounter.

This research revealed the mechanisms and processes involved in conducting informal peer education in university settings and the role of humour in communication around issues of sexual health and sexual decisions. In distinguishing informal peer education from ordinary conversation, humour contributes to creating an environment and encouraging the conversion from discussion to consultation and education within peer conversation. Humour can be useful in peer education practice firstly by drawing an audience (formally or informally) to a peer educator and establishing connection, camaraderie, familiarity and interest through making the peer educator appear relatable, engaging and entertaining. In developing the pathways to unlocking peer educative moments, humour fosters intimacy and trust between the participants of the interaction. Peers are able to feel comfortable and encouraged to share experiences, perspectives, opinions and thoughts which then promotes avenues for critical engagement and information dissemination familiar to peer education practice. Broaching subjects and topics that are typically secretive, private and personal such as sexual decisions in forum spaces needs to be cautiously handled. Humour, in its capacity to smooth over tension and 'lighten' 
the tone of a discussion, allows this process to occur more readily and often. Humour could simultaneously contain elements of harm in the way a joke is made or received. In acknowledging this, careful management of the device must be undertaken to ensure humour is appropriately drawn on to further moments of peer education.

HIV/AIDS programmes could evaluate potential peer educators, their personality traits, skills and qualities and assess their abilities to draw on humour in conversations with peers. The programmes could also facilitate training that encourages appropriate and effective humour use in peer education practice. The ability to share a joke, tease one another affectionately, participate in conversation that is entertaining shapes intimate sharing discussion, the foundation of peer education. Recognising, harnessing and utilising humour in this form may assist peer education, particularly in informal interactions.

Acknowledgements - This article is based research conducted by Silvie Cooper, as part of her master's degree in Health Sociology, and supervised by David Dickinson. We thank all the peer educators who participated in this research. We are grateful for their enthusiasm, insight, wit and openness. The Careers, Counselling and Development Unit (CCDU) at Wits University was instrumental to the success of the research and we acknowledge Vinoba Krishna and the Unit for their professionalism and cooperation. We also thank Catherine Cunningham, Sarah Mitchell and Stephen Thompson, as well as an anonymous reviewer for the comments they provided on earlier versions of this article. Additionally the continued and generous support of the National Research Foundation (NRF) and the Andrew W Mellon Foundation is much appreciated.

The authors - Silvie Cooper is a PhD candidate in the Sociology Department at Wits University. Her research interests include health promotion, peer education, contested conditions and illness experience. David Dickinson is Professor of Sociology at Wits University. His research interests include peer education and alternative theories of AIDS in South African townships.

\section{References}

Berry L. 2010. 3.4\% of tertiary students HIV-positive. Available at http://www.engineeringnews.co.za, 16 April 2010, [accessed 3 May 2010].

Campbell C, MacPhail C. 2002. Peer education, gender and the development of critical consciousness: participatory HIV prevention by South African youth. Social Sciences \& Medicine 55: 331-345.

CCDU (Careers, Counselling and Development Unit). 2011. Wits CCDU Peer Volunteer Programme. Available at http:// web.wits.ac.za/Prospective/StudentServices/CCDU/ PeerVolunteerProgramme.htm [accessed 4 February 2011].

Cooper S. 2011. The role of peer educators in their peers' negotiation of sexual decisions: a Wits University case study. MA Research Project, University of the Witwatersrand. Available at http://wiredspace.wits.ac.za/handle/10539/10169 [accessed 08 October 2012].

CHE (Council on Higher Education) Higher Education Quality Committee. 2008. Executive summaryAudit report on the University of the Witwatersrand, Johannesburg. Pretoria: CHE.

Dickinson D. 2009. Changing the course of AIDS: Peer education in South Africa and its lessons for the global crisis. Ithaca, New York: Cornell University Press.

Giddens A. 2006. Sociology (5th edn). Cambridge: Polity Press. Green J. 2001. Peer education. Promotion \& Education 8: 65-68. 
Green EC. 2003. Rethinking AIDS prevention: Learning from successes in developing countries. Westport: Greenwood Publishing Group.

Johnson MK, Berg JA, Sirotzki T. 2007. Differentiation in self-perceived adulthood: Extending the Confluence Model of Subjective Age Identity. Social Psychology Quarterly 70: 243-261.

Meyer JC. 2000. Humor as a double-edged sword: Four functions of humor in communication. Communication Theory 10: 310-331.

Nutbeam D. 2006. Using theory to guide changing individual behaviour. In: Davies M, MacDowall W (eds), Health promotion theory. Berkshire (UK): Open University Press.

Ochieng BMN. 2003. Adolescent health promotion: The value of being a peer leader in a health education/promotion peer education programme. Health Education Journal 62: 61-72.

Sciacca J. 1987. Student peer health education: a powerful yet inexpensive helping strategy. The Peer Facilitator Quarterly 5: 4-6.

Shepherd J, Weare K, Turner G. 1997. Peer-led sexual health promotion with young gay and bisexual men-Results of the HAPEER Project. Health Education 97: 204-212.

Turner G, Shepherd, J. 1999. A method in search of a theory: peer education and health promotion. Health Education Research Theory \& Practice 14: 235-247.

UNESCO (United Nations Educational, Scientific and Cultural Organization). 1999. Peer education and HIV/AIDS: Concepts, uses and challenges. Working document for the International Consultation on Peer Education and HIV/AIDS, 18-21 April 1999, Kingston, Jamaica.

Visser MJ. 2007. HIV/AIDS prevention through peer education and support in secondary schools in South Africa. Journal of Social Aspects of HIV/AIDS 4: 678-694. 